Acta Crystallographica Section A

Foundations of Crystallography

ISSN 0108-7673

\section{Celebrating 100 years of $X$-ray crystallography}

\author{
S. W. Wilkins
}

CSIRO, Materials Science and Engineering, Private Bag 33, Clayton South MDC, VIC 3169, Australia

11 November 2012 marks the centenary of the reading of the paper by William Lawrence Bragg (WLB) to the Cambridge Philosophical Society outlining the foundations of X-ray crystallography. It included the derivation of the first correct atomic structure of a crystal, namely that of zinc blende, based on the X-ray diffraction pattern recorded by Friedrich, Knipping and Laue in the spring of 1912. At the time of the lecture, Lawrence Bragg (as he later preferred to be called) was 22 years old and still a research student in the Cavendish Laboratory.

This special issue of Acta Crystallographica Section A is dedicated to commemorating this landmark scientific event, the ramifications of which have served as a wellspring for many other branches of science, including structural chemistry, mineralogy, materials science, solid-state physics and molecular biology. It is very fitting that a Bragg centennial issue be published in Acta Crystallographica, as it was Lawrence Bragg who was a major influence behind the formation of the International Union of Crystallography (IUCr) and Acta Crystallographica more than six decades ago. Lawrence Bragg also served as the inaugural President of the IUCr Executive Committee. A sense of the development of crystallography over the past six decades can be obtained by looking at the most frequently cited articles in Acta Crystallographica as listed on the IUCr Journals website.

The breakthrough by Lawrence Bragg did not come in isolation (e.g. see Ewald, 1962; Phillips, 1979, p. 88; Perutz, 1990; Jenkin, 2008, 2012). Having entered the Cavendish to work under J. J. Thomson, he lost interest in the project he was given and in the summer of 1912 he joined the family for a vacation on the Yorkshire coast. There his father, William Henry Bragg (WHB), then Professor of Physics at Leeds, was pondering on a letter from Germany reporting on the experiments of Laue and colleagues, and discussed this work with Lawrence. While strongly suggesting that X-rays were waves and diffracted by the crystal, the explanation by Laue appeared incomplete and unconvincing. William had for some time held to a neutral-pair hypothesis for the nature of X-rays. Not yet convinced of the wave nature of X-rays by the Laue experiments, William continued to adhere to his neutral-pair model, especially in lively exchanges with Barkla, although he was groping for a reconciliation between apparent particle and wave-like properties of X-rays.

On returning to Cambridge, Lawrence reflected more deeply on the nature of the pattern recorded by Laue and colleagues. Some key issues were that Laue had assumed that the spectrum from his X-ray source was so impure that what they needed to do to get observable diffraction effects was to use their X-ray source to generate fluorescence in the crystal. It would be, they assumed, the fluorescent radiation that would be diffracted by the same crystal (i.e. they were seeking to observe what subsequently became known as the X-ray Kossel effect). For this reason, they chose copper sulfate as one of their early samples for study in order to excite fluorescence by the relatively heavy atoms of copper.

Lawrence grappled with and sought to treat correctly three basic aspects of the phenomenon observed by Laue and colleagues, namely:

(i) the nature of the radiation spectrum being diffracted by the crystal; 
(ii) the shape of the spots in the diffraction pattern; and

(iii) the nature of the lattice (Laue had wrongly assumed a simple cubic lattice for zinc blende) and the correct indexing of the diffraction pattern.

It is reported (Phillips, 1979, p. 75) that while Lawrence was walking along the Backs in Cambridge one day in the late autumn of 1912, in a flash of insight he conceived of the relatively simple explanation that the diffraction patterns from zinc blende observed by Laue and colleagues could be ascribed to the reflection of electromagnetic waves of short wavelength from planes of atoms in the crystal. Moreover, that this diffraction information provided a means for determining the atomic structures of crystals. In getting this explanation to work for zinc blende, Lawrence firstly had to assume that the spectrum of incident radiation on the crystal was essentially continuous (he called it a 'pulse'), compared with Laue, who had assumed a small number of discrete wavelengths, and secondly he had to assume that the lattice for zinc blende was of the face-centred cubic type, not simple cubic. In his understanding of crystal structures, he was aided by discussions with his friend Gosling, who had described to him some of W. J. Pope's ideas on crystal lattices, and also with Pope himself.

Lawrence's ideas presented to the Cambridge Philosophical Society outlining these insights and results were published shortly afterwards in the Proceedings [W. L. Bragg, 1912a; see also W. H. Bragg in Nature on 28 November and W. L. Bragg in Nature on 5 December (W. L. Bragg, 1912b)]. The paper contained a statement of what has come to be called Bragg's law (albeit in a cosine form). There was still some uncertainty in his mind as to the nature of X-rays, whether the waves that were diffracted were in fact X-rays and whether the waves were accompanied by some form of particles. For this reason, and also in deference to his father's views, Lawrence titled his paper On the diffraction of short electromagnetic waves by a crystal. Once Lawrence's interpretation of the patterns produced by Laue and colleagues was discussed with his father, William rapidly accepted the wave interpretation of X-rays and from this understanding (W. L. Bragg, 1962), and using the substantial manpower and technical resources at his disposal in Leeds, he quickly developed an X-ray spectrometer for studying fluorescent radiation, using Bragg's law and a crystal of known $d$-spacing as an analyzer crystal. At the time, Lawrence was busy collecting Laue patterns from simple alkali halide crystals and solving their structures. However, compared to the more quantitative and direct possibilities of collecting diffraction data using the spectrometer developed by his father, the limitations of the Lauepattern method were very evident to him.

There followed major works by WHB on both the determination of characteristic wavelengths and attenuation factors (using rock salt, the structure and lattice parameter for which had earlier been derived by Lawrence) and a seminal paper by Lawrence on alkali halides including rock salt. A joint paper soon followed on the structure of diamond. Exciting opportunities for applying the new techniques for atomic structure determination and X-ray spectrometry/diffractometry abounded and their work flourished. In WHB's hands the spectroscopic investigations proved very fruitful. At the request of Rutherford, two of Rutherford's protégés at Manchester, namely Moseley and C. G. Darwin, were asked to confirm WHB's results with the aim that they all published simultaneously (see Jenkin, 2008, pp. 345349). WHB subsequently withdrew from research in the spectroscopy area.

Lawrence concentrated more on crystal structure determination, while WHB became more involved in the physics of X-ray diffraction. In 1915, Lawrence and his father were awarded the Nobel Prize for Physics. Lawrence was then only 25 years old and remains the youngest Nobel Prize winner ever and the only one to celebrate the jubilee of his award (see 50 Years a Winner, 1965).

Over the next 50 years or so, Lawrence played an instrumental role in the development of several other wholly new areas of science, such as metal physics, structural biology and radio astronomy. A signature feature of his work was the ability to find simple approaches to difficult problems, to have a powerful instinct for knowing which areas of science were worth pursuing, and to constructively guide and inspire those around him. In the words of Alan Mackay (1991), "Bragg had a huge number of concrete models and analogies 'to hand' in his mind. These he could deploy and manoeuvre with great appropriateness" and further, that 'Together, the Braggs had a superb vision that the microworld was just like the everyday world, only smaller. With this vision the Braggs revolutionized chemistry, metallurgy, mineralogy and later biology.'

For much of his life Lawrence persevered against the lingering, widely held misapprehension that the pioneering step in the development of X-ray crystallography had been made by his father, although at various times Lawrence had outlined the relative roles each had played. In this regard, the following quotation from a letter from Lawrence to P. P. Ewald (1962), the founding editor of Acta Crystallographica, in response to 
an article and letter by Ewald written about WHB, is relevant:

On my return to Cambridge I restudied Laue's results and explained the $\mathrm{ZnS}$ spots as being due to diffraction by a facecentred cubic lattice (Oct. 1912). This, I think, convinced my father that they were diffraction effects, but he still thought that there might be electromagnetic waves associated with the $\mathrm{X}$ rays and in deference to his views, I called my paper (Nov. 1912) 'The diffraction of short electromagnetic waves by a crystal'. My father was still wavering when he wrote the note to 'Nature' on Nov. 28th which you quote. But just about that time I showed that $\mathrm{X}$ rays were specularly reflected over a range of angles by cleavage planes of mica ('Nature', Dec. 12, 1912) and my father at once examined the rays reflected from mica with an ionization chamber and convinced himself that they were really $\mathrm{X}$ rays. This led to his designing the $\mathrm{X}$ ray spectrometer. I had no hand in planning the spectrometer, but while this work was going on I had worked out the structure of $\mathrm{NaCl}$ and $\mathrm{KCl}$ by Laue photographs, and that is how my father came to use rock-salt for the curves in our first joint paper 'The Reflexion of X rays by Crystals', on which we worked together during the Xmas holidays of 1912-13. These results of course showed the immensely greater power of the spectrometer for analysing crystals. I was very much teased at the time for upsetting my father's theory! But you will see how much my father's work at Leeds, and mine at Cambridge, were interwoven at that early time.

The present special issue of Acta Crystallographica Section A contains a collection of papers contributed by speakers at the Bragg Centennial Symposium held in Adelaide (home to W. H. Bragg and family from 1886 to 1909) on 6 December 2012. The aim of the symposium was to explore some of the historical context and personal links to the Braggs' work, as well as to feature some of the broader scientific and social impact of their work.

As a guide to the contents of this special issue, the article Lawrence Bragg's interest in the deformation of metals and 1950-1953 in the Cavendish - a worm's-eye view by Anthony Kelly describes the early work in the Cavendish on metal physics and microdiffraction, with particular emphasis on understanding the nature and properties of dislocations. The area of microdiffraction and WLB's work in this area is also addressed by John Spence in his article Lawrence Bragg, microdiffraction and $X$-ray lasers, and provides a link from the pioneering work of WLB into current state-of-the-art microdiffraction using convergent-beam electron diffraction methods and femtosecond-scale time resolution microdiffraction with $\mathrm{X}$-rays emanating from $\mathrm{X}$-ray freeelectron lasers. WLB's involvement in and encouragement of the application of X-ray crystallography to determining the structures of biological macromolecules is addressed in the obituary for Sir Lawrence Bragg by Max Perutz (1971) (an extract of which is kindly repro- duced by permission of the Nature Publishing Group), the article by Brian Matthews entitled The Bragg legacy: early days in macromolecular crystallography and in an overview article on the Evolution of diffraction methods for solving crystal structures by Wayne Hendrickson. In addition, some personal recollections of the application of crystallography to drug discovery are provided by Peter Colman. The application of Bragg's law in fields other than X-rays is treated by Thomas Mason et al., who describe the early days of neutron diffraction in their article The early development of neutron diffraction: science in the wings of the Manhattan Project, and by Colin Humphreys in The significance of Bragg's law in electron diffraction and microscopy, and Bragg's second law. An account of the internal deliberations of the Nobel Committees leading up to the award of the Nobel Prize to the Braggs is provided in the article by Anders Liljas entitled Background to the Nobel Prize to the Braggs. A verbal portrait of Lawrence Bragg as seen by those closest to him, namely his family, is provided by his younger daughter Patience Thomson in the form of a tribute.

As a tribute to the work of Sir Lawrence Bragg and in recognition of his Australian origins, the Society of Crystallographers in Australia and New Zealand (SCANZ) has instigated the striking of a medal in his honour. This medal is to be awarded approximately biennially (at national meetings of SCANZ) for outstanding achievements in the field of crystallography by a scientist working largely in Australia and/or New Zealand. The first Lawrence Bragg Medal of SCANZ was awarded at the AsCA 12/CRYSTAL 28 Conference in Adelaide that immediately preceded the Bragg Centennial Symposium.

In preparing this short introduction to this special commemorative issue, I have drawn heavily on the sources below and especially the monumental Royal Society biographical memoir on Lawrence Bragg by David Phillips, and also from discussions with John Jenkin. In looking to the future of our field, we might do no worse than adopting a dictum of Lawrence Bragg, namely 'Do not follow the fashion and do not hesitate to try an experiment which the theorists hold to be stupid' (Mackay, 1991).

\section{References}

Bragg, W. H. (1912). Nature (London), 90, 360-361.

Bragg, W. L. (1912a). Proc. Cambridge Philos. Soc. 17, $43-57$.

Bragg, W. L. (1912b). Nature (London), 90, 410.

Bragg, W. L. (1962). Letter to P. P. Ewald dated 5 February (Royal Institution Archives, Record No: RI MS WLB 44c_41).

Colman, P. M. (2013). Acta Cryst. A69, 60-62.

Ewald, P. P. (1962). Fifty Years of X-ray Diffraction, edited by P. P. Ewald, ch. 5. Utrecht: N. V. A. Oosthoek's Uitgeversmattschappij. 


\section{Bragg centennial}

50 Years a Winner (1965). BBC documentary commemorating the 50th anniversary of the Nobel Prize awarded to W. L. Bragg (University of Adelaide Archives).

Hendrickson, W. A. (2013). Acta Cryst. A69, 51-59.

Humphreys, C. J. (2013). Acta Cryst. A69, 45-50.

Jenkin, J. (2008). William and Lawrence Bragg, Father and Son. Oxford University Press.

Jenkin, J. (2012). Austr. Phys. 49, 75-79.

Kelly, A. (2013). Acta Cryst. A69, 16-24.

Liljas, A. (2013). Acta Cryst. A69, 10-15.
Mackay, A. (1991). Nature (London), 351, 279-280.

Mason, T. E., Gawne, T. J., Nagler, S. E., Nestor, M. B. \& Carpenter, J. M. (2013). Acta Cryst. A69, 37-44.

Matthews, B. W. (2013). Acta Cryst. A69, 34-36.

Perutz, M. F. (1971). Nature (London), 233, 74-76.

Perutz, M. F. (1990). Acta Cryst. A46, 633-643.

Phillips, D. (1979). Biographical Memoirs of Fellows of the Royal Society, Vol. 25, pp. 75-143.

Spence, J. C. H. (2013). Acta Cryst. A69, 25-33.

Thomson, P. (2013). Acta Cryst. A69, 5-7. 